\title{
Textos latinos para un arte de la jardinería en Roma
}

\author{
Juan Antonio González Iglesias \\ Universidad de Salamanca
}

Título: Textos latinos para un arte de la jardinería en Roma.

Resumen: Este artículo propone una serie de textos que configuran un arte de la jardinería en latín. En el momento clásico, el de la humanitas, la prosa de Cicerón y los hexámetros didácticos de Virgilio atestiguan inequívocamente la presencia de jardines diferentes de los huertos y la necesidad de un arte (un conocimiento teóricopráctico) adecuado a los jardines. Columela en época postclásica y Paladio en época tardía cumplirán el encargo poético de Virgilio. No existe en latín un tratado de ars topiaria autónomo, pero sí zonas de jardinería en los tratados de horticultura, independientes ya de los de agricultura.

Palabras clave: Hortus, topia, topiarius, ars, arte de los jardines.

Fecha de recepción: 22/12/2021.

Fecha de aceptación: 27/12/2021.
Title: Latin Texts for an Art of Gardening in Rome.

Abstract: This paper proposes a series of texts that shape an art of gardening in Latin. In the classical period, that of the humanitas, Cicero's prose and Virgil's didactic hexameters unequivocally testify to the presence of gardens other than orchards and the need for an art (a theoretical-practical knowledge) suited to themselves. Columella in the post-classical period and Palladius in the Late Antiquity fulfilled Virgil's poetic commission. There is no autonomous treatise on the ars topiaria in Latin, but there are areas of gardening in the treatises on horticulture, independent of those on agriculture.

Key words: Hortus, topia, topiarius, ars, art of gardens.

Date of Receipt: 22/12/2021.

Date of Approval: 27/12/2021.

\section{Del huerto al Jardín}

Si, en términos generales, las culturas mediterráneas de la Antigüedad constituyen el germen de lo que entendemos por jardín, lo definitivo para su concepto moderno se decide en las villas de la Roma clásica y tardía. La civilización romana, por lo que se refiere tanto a los jardines como a la teoría acerca de los mismos, funciona también en esto como puente perfecto entre la cultura helénica y las europeas que se irán desgajando del Imperio romano. 
La concreción del jardín, del arte de los jardines, coincidirá con la apertura de Roma al mundo Mediterráneo, que entonces equivalía al mundo: "longtemps, les Romains ne possédèrent que des champs et des potagers en dehors des maisons de leur ville: ils n'eurent des parcs et des jardins qu'après avoir achevé la conquête du monde" ${ }^{1}$.

Dos son los accesos directos que tenemos a los jardines romanos: la literatura y la arqueología. Los textos literarios ofrecen, en prosa y en verso, un panorama tan vívido que podemos lograr una imagen bien perfilada de lo que eran y lo que significaban, incluso en los detalles de no pocos de ellos y en los distintos tipos de jardinería. Al margen de que pueda resultar paradójico, tales descripciones se nos antojan más directas incluso que las arqueológicas, que muy a menudo sufren la interferencia de intervenciones sumadas en estratos que, por la propia naturaleza de la vegetación, opaca el contorno de lo que fueron. La suma de literatura y arqueología nos ofrece una concepción en la que se alimentan ambas visiones. Algunas otras fuentes, como las meramente jurídicas, completan tamaño panorama (pensemos en la Ley de las XII Tablas).

En lo esencial tenemos perfectamente definidos y clasificados los jardines romanos en la monografía de Grimal, Les jardins romains ${ }^{2}$, cuyo enfoque es dominantemente literario (sin excluir datos arqueológicos), además de presentar un buen muestrario de ilustraciones. Por dicha senda avanzó Segura Munguía ${ }^{3}$, quien además ofrece un corpus de traducciones castellanas de textos latinos sobre jardines tan rico que deviene en una antología de textos sobre el asunto; si a ello se añade la abundancia de ilustraciones, vale concluir que en el vasto ámbito de la Antigüedad (no solo para Roma) se trata de una obra tan imprescindible como la de Grimal. En cambio, Farrar ${ }^{4}$ los clasifica desde una ladera opuesta: su enfoque es fundamentalmente arqueológico y lo complementa con datos librescos. Después de analizar el trasfondo histórico, dibuja un itinerario que parte de los jardines egipcios y mesopotámicos antes de cruzar por los de la Grecia antigua y helenística, los persas y los etruscos. Sitúa los

\footnotetext{
1 Pierre Grimal, Les Jardins romains, Paris, Presses Universitaires de France, 1969, p. 1.

2 Grimal, op. cit.

3 Santiago Segura Munguía, Los jardines en la Antigüedad, ed. Javier Torres Ripa, Bilbao, Universidad de Deusto, 2005.

4 Linda Farrar, Ancient Roman Gardens, Stroud, Sutton Publishing, 2001.
} 
romanos en el dominio residencial, describe cómo el desarrollo del jardín se vinculó primero a la villa rústica y luego a las urbanas y suburbanas. Como los otros estudiosos, aunque en mayor grado, atiende a los elementos arquitectónicos y ornamentales (estanques, fuentes, esculturas), a la descripción de la flora y fauna y también de los aspectos técnicos del arte topiaria.

En efecto, todas las fuentes latinas nos indican que los romanos percibían la jardinería como un arte, con todas las consecuencias que eso tiene en su organización del saber. La jardinería es un arte que se va haciendo autónomo respecto a la horticultura, y esta previamente ha cobrado autonomía respecto a la agricultura. Por otro lado, la jardinería artística parece desgajarse también de la arquitectura y de la pintura. Tiene un nombre que ha gozado de gran fortuna entre los especialistas (teóricos y prácticos) en la Modernidad, pero que sigue siendo en lo esencial un concepto pendiente de una definición bien perfilada dentro del mundo antiguo: ars topiaria. De hecho, el término, de muy amplia acepción, no fue analizado a fondo en su dimensión histórica y teórica hasta el año 2000, cuando se celebró el congreso Topiaria. Architetture e sculture vegetali nel giardino occidentale dall'antichità a oggi. Como iniciativa típicamente italiana (la convocó el organismo Grandi Giardini Italiani), inició sus reflexiones analizando la continuidad directa con la Roma antigua y tuvo lugar, no por casualidad, en una de las más hermosas y grandes villas barrocas del Véneto: la Villa Allegri Averdi, en Grezzana, cerca de Verona, que preserva esta gran tradición itálica tanto en su dimensión agronómica (hoy integrada en el agroturismo) como en la de la jardinería más refinada ${ }^{5}$. El concepto clásico de adecuación entre el contenido y el lugar se remonta literariamente a Cicerón (al que vemos/leemos hablar del tema en diálogos y cartas que tratan de villas especialmente bellas) y arquitectónicamente a Vitrubio, por su autor, Bianchi, y la escuela véneta de las grandes villas de Palladio.

Las aproximaciones recientes a los jardines romanos mantienen la mirada interdisciplinar, holística incluso, pero se articulan en torno a la historia. Muñoz-Delgado de la Mata ha discurrido sobre ellos como imagen

5 Topiaria. Architetture e sculture vegetali nel giardino occidentale dall'antichità a oggi, ed. Margherita Azzi Visentini, Treviso, Edizioni Fondazione Benetton Studi Ricerche/Canova, 2004. 
de poder y mecenazgo ${ }^{6}$. Y Pons Pujol cataloga los siguientes enfoques metodológicos a la hora de estudiarlos: "historia antigua, arqueología, pintura, musivaria"'. En el volumen colectivo en el que se recoge dicho artículo, se enmarcan de nuevo en el contexto de la Antigüedad. Nosotros vamos a completar tales perspectivas desde la filología, como hiciera Grimal, ciñéndonos a la búsqueda a través de los textos de un arte posible de los jardines, es decir, de la visión teórico-práctica de los propios romanos reflejada en sus obras.

\section{El PRIMER NOMBRE DEL JARDÍN: HORTVS}

A pesar de que distinguiremos a menudo entre huerto y jardín, debemos ser conscientes de que la segunda de estas palabras guarda una relación etimológica indoeuropea con la latina hortus y ambas con la idea de un cercado o vallado que delimita un terreno, sea para el ganado o para las plantas que lo alimentan, directa o indirectamente. Esto es un universal antropológico que los clásicos expresan sin ambages: "étymologiquement, physiquement et ontologiquement, le jardin est un enclos: une entité découpée dans le territoire rural ou urbain, individualisée et autonome"8.

Situado a las afueras o en una gran finca alejada de la urbe, hay una evolución larga del concepto: desde el huerto y casi el corral hasta llegar al refinado recinto vegetal contenido en una villa y destinado al placer de los sentidos y de la inteligencia.

El léxico que emplean para el jardín los escritores del corpus latino gira predominantemente en torno al término hortus, frecuentísimo y con el sentido primero (en la cronología y en la prevalencia) de "huerto". Su

6 Cristina Muñoz-Delgado de Mata, "Los jardines de la Roma clásica: imagen de poder y mecenazgo", Cuadernos de Arqueología de la Universidad de Navarra, 24 (2016), pp. 1-20.

7 Lluís Pons Pujol, "Enfoques metodológicos en el estudio de los jardines romanos: historia antigua, arqueología, pintura, musivaria”, en Paradeisos. Horti. Los jardines de la Antigüedad, ed. Lluís Pons Pujol, Universitat de Barcelona, Barcelona, 2020, pp. 83-116.

8 Hervé Brunon y Monique Mosser, "L'enclos comme parcelle et totalité du monde: pour une approche holistique de l'art des jardins", Ligeia, 20, 73-76 (2007), pp. 59-75 (p. 59). 
diminutivo hortuli es a veces sinónimo, si bien otras sugiere un tamaño menor o los habituales vínculos afectivos y, en alguna ocasión, precisa que el autor está hablando de un jardín más que de un huerto. El mejor ejemplo lo tenemos en Catulo, 61. Aunque sea en un símil, la imagen que usa el poeta proviene del mundo real:

\section{talis in vario solet \\ divitis domini hortulo \\ stare flos hyacinthinus. \\ sed moraris, abit dies. \\ prodeas nova nupta (vv. 87-91).}

Como en ameno jardin-

cillo de rico señor

brota la flor del jacinto,

así tú. Pero te estás

retrasando. Se va el día.

Nueva novia, marcha ya?.

Si Catulo representa la finura del romano helenizado, Fedro, griego romanizado, está a su altura cuando escribe "domum politam et delicatos hortulos" (Phaedrus, Fabulae Aesopiae 4.5.26, 4.5.34): "una casa elegante y unos refinados jardines".

Por lo demás, el vocabulario esencial que emplean los romanos para acercarse a la realidad del jardín es muy escueto y gira en torno a hortus, salvo una línea léxica y literaria diferente (la de topia) de la que nos ocuparemos más tarde. Hortulanus casi siempre se refiere al hortelano más que al jardinero. En Apuleyo el hortelano es uno de los personajes, pero se trata de alguien que cultiva alimentos. Y hasta el cerdo hortulanus en el tratado culinario (un "arte de cocinar") de Apicio es lo que nosotros llamaríamos "cerdo de granja", criado con productos de la huerta. El nombre del oficio, horticola, es raro; aparece solo tardíamente en una glosa a Isidoro. Y resulta llamativo que no se documente el sustantivo horticultura, que podría haber dado nombre a tratados similares a los De Agricultura.

9 Catulo, Poesías, ed. bilingüe de José Carlos Fernández Corte, trad. Juan Antonio González Iglesias, Madrid, Cátedra, 2006, pp. 314-315. 


\section{El JARDín LiTERARIO: LA INCLUSIÓN DEL HORTVS EN LA DOMVS}

Hay un doble concepto de jardín literario: el que conocemos por los testimonios en verso o en prosa y el construido a partir de las lecturas de su dueño. Pueden confluir ambos y no sorprenderá que suceda —en la medida en que un lector apasionado proyecte temas, nombres o motivos literarios en el jardín que construye y después nos hable en sus textos del que él mismo ha erigido-. La cultura grecolatina es literaria porque las cosas se transmitían en los textos de los escritores y las letras informaban la realidad, gobernada por dirigentes cultos. Eso ocurre también con los jardines, que en gran medida son literarios.

El modelo más alto es Cicerón. En los de su villa de Túsculo tenía dos espacios distintos, una Academia (que albergaba una especie de gimnasio, entendido más a la romana como lugar de esparcimiento) y un Liceo (sede de la biblioteca), destinados a las conversaciones filosóficas. En Tusculanae disputationes 2, 9 nos cuenta cómo se desplazaba por ambas zonas:

Nostra autem memoria Philo, quem nos frequenter audivimus, instituit alio tempore rhetorum praecepta tradere, alio philosophorum: ad quam nos consuetudinem a familiaribus nostris adducti in Tusculano, quod datum est temporis nobis, in eo consumpsimus. Itaque cum ante meridiem dictioni operam dedissemus, sicut pridie feceramus, post meridiem in Academiam descendimus.

En nuestro tiempo Filón, cuyas lecciones escuché muchas veces, estableció que las enseñanzas de los maestros de retórica se debían transmitir en un determinado momento y las de los filósofos en otro. Siguiendo esa costumbre, a petición de mis amigos, yo he repartido así el tiempo libre en mi villa de Túsculo. Así, hoy hemos dedicado la mañana a la oratoria, como hicimos ayer, y por la tarde bajamos a la Academia.

Similar descripción la bosqueja en una carta a Ático (Ad Att. 1, 4). Sin embargo, la inclusión del jardín en la villa se perfila con concisión sentenciosa en el cierre de otra misiva dirigida a su hermano Quinto ( $A d$ Quintum 2, 8). La despide con una invitación a su pariente. Los placeres 
de la villa quedan resumidos en esta frase lapidaria, que vale para muchas de las romanas y numerosas residencias de los siglos posteriores, hasta hoy: "Hortus domi est" ("Hay un jardín en esta casa").

\section{El JARDÍN EN EL MOMENTO DE LA HVMANITAS}

El hecho de que Cicerón sea el más fecundo prosista en dar noticia de sus jardines "filosóficos" no es casual, dado que la noción de humanitas tiene en ellos una de sus mejores concreciones. Como tantos otros elementos valiosos de la Modernidad, el jardín —en su faceta pública y en los diferentes formatos y tamaños de la privada- procede de la síntesis entre la cultura helenística más refinada y el utilitarismo romano. Si esto debe cifrarse históricamente, ese momento ideal es el de la humanitas, el arco temporal que va desde la Roma del círculo de los Escipiones a la de Cicerón: de mediados del siglo II a mediados del I a.C. Nuestro concepto de jardín se fragua justo cuando en que la noción de humanitas está plenamente elaborada. Son sincrónicos: el jardín presenta al sujeto en el mundo, le hace comprensibles —incluso placenteros- los límites que definen la condición humana, le brinda la amenidad de nuestro paso por la tierra, concilia el gusto por las bellezas de la naturaleza y del arte y, en fin, propicia la empatía contenida en la pietas.

En una breve carta a Varrón (ad Fam. 9.4), sentenciosa toda ella (ochenta palabras justas), Cicerón acuña una fórmula que se ha hecho célebre y que suele traducirse de manera superficial. El gran orador, una vez más desde su villa en Túsculo, se muestra dispuesto a aceptar que Varrón venga o no a visitarlo. Habla de la necesidad de las cosas, invocando lo esencial y la aceptación. Y al final de la epístola, le apostrofa: "Tu si minus ad nos, nos accurremus ad te" ('si no vienes tú a verme iré yo a verte a ti'). La aportación definitiva a la teoría (universal, no solo grecorromana) del jardín estriba de nuevo en la cláusula final: "si hortum in bibliotheca habes, deerit nibil' ('si tienes un jardín en la biblioteca, no te faltará nada').

La proyección universal de una idea grecorromana es lo que conocemos como clásico. La sentencia ciceroniana, casi axiomática, se ha divulgado por ejemplo en el proverbio inglés: "If you have a garden and a library, you have everything you need". Sin embargo, conviene releer 
las palabras de Cicerón sobre la singular confluencia de dos entornos característicos. El jardín se desvela como lugar de asueto individual que, combinado con la biblioteca, contiene en pequeño — es decir, dentro de sus límites - todo lo necesario del mundo. Esa dimensión en miniatura se mantendrá en la Modernidad: "La vocation des jardins à rassembler en un microcosme la totalité du monde reste, évidemment, au cœur de la tradition des jardins botaniques" 10 . Dado que el verbo deerit ("faltará") no lleva el habitual dativo que rigen los compuestos de sum, podemos interpretar que Cicerón apela a Varrón como segunda persona concreta (tibi), y en realidad como una segunda persona impersonal (a cualquiera que posea un jardín no le faltará nada). La segunda se deduce de la primera, puesto que ambas se basan en la experiencia del propio Cicerón, transmitida con la máxima concentración en las cinceladas frases de la carta, hecha casi de apotegmas.

El jardín es también lugar de encuentro interpersonal, propicio para la más noble vida social y más aún para la cultura, ya que ambas se contienen en la humanitas. Puesto que Cicerón se propone ir a visitar a Varrón, le anuncia: "si tú no vienes a verme a mí (que tengo jardín y biblioteca), acudiré raudo yo a visitarte. Si tienes un jardín en la biblioteca, no nos faltará nada”. Entenderemos que el dativo que aquí falta sería nobis (a nosotros, a los interlocutores que ahora nos comunicamos por carta pero que conversaremos de todo esto cuando nos veamos). Hay que considerar que un poco más arriba le ha dicho: "Sed de his etiam rebus, otiosi cum erimus, loquemur" ('de todas estas cosas ya hablaremos cuando tengamos tiempo libre’). El jardín se consagra al ocio, dos nociones que en latín están mucho más cerca, porque incluso fónicamente se conectan por una cuasi-paronomasia (cito los dos términos como se citan en la misiva del Arpinate): otium/hortum. La noción de otium va mucho allá de nuestro "tiempo libre". Es una categoría central en el funcionamiento de la sociedad, la cultura y la política romanas, un atributo de su grupo dirigente. El giro — por ampliación- de la Roma arcaica (nacionalista, tradicional y utilitaria) a la Roma clásica (helenizada, universal y abierta a los intereses culturales) se da también en la palabra hortus. En el hortus tiene que caber el negotium anterior y

10 Brunon y Mosser, op. cit., p. 70. 
el otium actual como rasgo esencial de la humanitas. Muy claramente lo expone Muñoz-Delgado de Mata:

Los romanos no se limitaron meramente a copiar los modelos griegos, sino que los adaptaron a sus propias costumbres, valores y tradiciones, confiriendo así al jardín no sólo una mera función ornamental o de descanso, sino también agrícola y hortícola. De esta manera, otium y negotium quedaban relacionados, resolviendo la disputa que se venía recogiendo en las fuentes desde tiempos atrás ${ }^{11}$.

Dado que Cicerón planteaba a Varrón, al principio de la carta, la aceptación de las cosas necesarias, es decir, lo esencial: "si venturus es, scito necesse

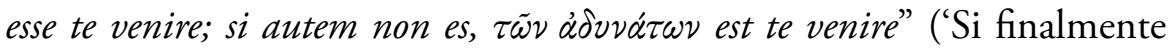
acabas viniendo, será porque es algo necesario que vengas. Si finalmente no vienes, es porque tu venida se cuenta entre las cosas que no pueden suceder'), en un texto donde todo está tan ligado se advierte que el jardín es una de las cosas posibles, esenciales y, en el sentido filosófico, necesarias. Por eso declara: "si tienes un jardín, no (nos) faltará nada para conversar". El jardín no es imprescindible para la vida primaria, puramente material o manual. Sí que deviene filosóficamente necesario para quienes deseen dialogar sobre un tema. La litotes lo confirma ("nihil deerit"): entonces tendremos todo lo que la humanitas requiere.

La inclusión del jardín en la biblioteca también debe ser repensada. El jardín privado no aparece como un espacio exento, pues se incluye en la villa $y$, aunque su extensión sea tan grande que físicamente sea la biblioteca la incorporada al jardín, lo cierto es que conceptualmente el hortus se adentra in bibliotheca. Esto supone una curiosa inversión de las cosas tal como empezaron en Atenas. La Academia y el Liceo se alojaban en los respectivos jardines. Más arriba hemos visto cómo la biblioteca de Cicerón en Túsculo formaba parte del jardín (el llamado "Liceo"). Ahora los términos se invierten. El orden romano, en esa especie de traslación en miniatura de la realidad griega, coloca el jardín en el espacio de la bibliotheca. Probablemente dependa tan solo del punto de vista: si uno está en el jardín, ve que este tiene una biblioteca. Si está dentro, ve que la biblioteca cuenta con un jardín.

11 Muñoz-Delgado de la Mata, op. cit., p. 10. 
Cicerón caracteriza como modelo ideal de villa con jardín el de la suya propia. La consciencia que tiene de su clasicidad, comparable solo a la de Horacio, hace que adquiera dimensión universal el formato que plantea como requisito general de la humanitas. ¿Por qué? Porque en el jardín se dan, como hemos visto, todos los rasgos que definen la humanitas grecolatina. En realidad su evolución puede rastrearse como un capítulo de la literatura latina donde afloran las grandes líneas, las épocas, los géneros, la contraposición entre prosa y verso (es más, entre prosa técnica y verso sublime) y el seguro impacto de los clásicos sobre los textos posteriores.

\section{ARS TOPIARIA}

La noción de ars topiaria cuenta con pocos asientos en los textos romanos. En el volumen Topiaria. Architetture e sculture vegetali nel giardino occidentale dall'antichità a oggi ${ }^{12}$, hay dos aportaciones esenciales al respecto: Contini acometió una revisión sistemática y muy precisa de los clásicos que abordan los términos relacionados con la topiaria ${ }^{13}$. Más arriesgado es el análisis de Viscogliosi, cuya relectura de las voces esenciales (Opus topiarium, topiaria, topiarius) lo mueve a abrir la traducción de topiaria, siquiera como hipótesis, al concepto actual de "paisajista":

Ci si chiede, infatti, se con il termine opera topiaria non vada inteso il vero e proprio lavoro del giardiniere paesaggista, in modi e termini che hanno conosciuto evoluzioni e varianti anche consistenti nel corso dei circa due secoli in cui possiamo concentrare le relative testimonianze letterarie e archeologiche ${ }^{14}$.

Los testimonios literarios y arqueológicos — con sólida y coherente tradición helenística en ambos campos - relativos a este concepto se concentran en dos siglos: Cicerón, Vitrubio, los dos Plinios, Tácito y Suetonio,

12 VV. AA., op. cit.

13 Ibidem.

14 Alessandro Viscogliosi, “Topiaria: un'altra proposta di lettura nel mondo romano”, en Topiaria. Architetture e sculture vegetali nel giardino occidentale dall'antichità a oggi, ed. Margherita Azzi Visentini, Treviso, Edizioni Fondazione Benetton Studi Ricerche/Canova, 2004, pp. 16-21 (p. 20). 
por lo que atañe a las letras; el praetorium (antes praedium) de Sperlonga, el praetorium de Baias, la villa de Domiciano en los montes Albanos y, en su grado más alto, la villa Adriana. Viscogliosi ve en algunos de ellos una conexión directa entre la literatura y la arquitectura (entre los jardines de Sperlonga y el diseño vitrubiano) ${ }^{15}$. En todas funcionan los topia como "lugares, paisajes", reales o imaginarios, reproducidos a escala o creados por estos artistas, titulares de su propio arte.

Debemos precisar algunas cosas. El sustantivo latino, de estirpe griega, topia, -orum llegó hasta nosotros atestiguado solo en plural. Ese dato lingüístico inserto en lo literario apunta a que los jardines artísticos gozaban de unas dimensiones considerables y albergaban una pluralidad de tratamientos vegetales. Lo cual nos indica que las zonas artificiosas eran también un plurale tantum: dicho de otro modo, no podía hablarse de jardín artístico si solo había una zona o un punto (o solo una planta) que hubiera recibido ese oropel.

Topia parece una concreción de hortus, definida dentro de él tanto en lo espacial como en lo conceptual. Proponemos traducir topia por "zonas ajardinadas artísticamente", si leemos hortus como "jardín”. Otro correlato, probablemente para un momento anterior, podría ser "jardín de recreo o zona ajardinada" para topia, cuando hortus era prácticamente un "huerto". En uno u otro momento los topia estaban dentro del hortus.

Entre los profesionales del ramo, el hortulanus sería el jardinero en el sentido más amplio (desde el hortelano hasta jardinero en todas sus variantes), mientras que el topiarius sería el especialista (jardinero paisajista), a veces ya sin ninguna relación con el cultivo. Viscogliosi esboza ese paralelismo en relación con otro: "Non troppo diverso, invece, è il caso della Domus Aurea, i cui autori, Severo e Celere, non a caso non vengono definiti architetti, ma magistri ac machinatores, il che forse sta al termine architetti come topiarius stava a hortulanus" ${ }^{16}$.

El hecho de que topia se refiera en primer lugar a los paisajes pintados al fresco (el famoso pasaje de Vitrubio 7, 5, 2) y luego a los jardines artísticos o de fantasía, nos confirma que la topiaria era un ars, como lo era la pictura (de hecho parece ser un arte específico dentro del arte pictórico). Curiosamente, en la presentación histórica de los textos en Roma se ates-

15 Ibidem, p. 19.

16 Ibidem, p. 21. 
tigua primero la representación pictórica de lugares ajardinados famosos (reales o fantásticos) y después su plasmación física. Grimal es categórico sobre este punto: "l'objet essentiel de l'art topiaire est la composition de véritables tableaux". Lo dice a propósito de un conocido pasaje de Plinio el Viejo (N.H., 16,140): "Trahitur etiam in picturas operis topiarii" ('Se pone en pinturas de factura paisajística'). Por eso podríamos traducir topiaria por "paisajismo", que también podría valer primero para la pintura y luego para la jardinería. Grimal invoca el tecnicismo topiografía (mejor que topografía) usado por los especialistas en pintura y digno de trasladarse hoy para los profesionales del paisajismo ('topiógrafos' vs. los topógrafos).

Luego los jardines artísticos se asemejan a pinturas de jardines. Y también, añadimos, en un tercer plano, igualmente son vistos/leídos como écfrasis literarias de jardines (tampoco es casual que topia esté emparentado con topos, el locus communis de la retórica). Dicho horacianamente: ut pictura topia. Dicho retóricamente: los topoi pueden ser loci communes; compartidos, los topia pueden ser lugares extraordinarios, únicos en su artisticidad. Esa manera pictórica — y de fondo, poética — de ver el jardín se hará expansiva en dos sentidos: desde la época clásica se proyectará en toda la tradición occidental; y desde el hortus como jardín pervivirá en formatos más vastos en su diseño, no solo en sus formas más elaboradas (los topia). Así, también en la estela del Ars poetica de Horacio, Hunt definirá este arte en los siguientes términos: "the human action, whether contemporary or historical, usually contained ingredients derived from classical culture and required some verbal commentary upon the visual experience to enunciate the whole garden episode. Ut pictura hortus" ${ }^{17}$.

Topiaria referido al ars (según se deduce, aunque no haya pruebas de que ese sea el sustantivo omitido) aparece por vez primera y única en Cicerón. Por tanto, en rigor, se trata de un hápax. Es más, al ser esta su única aparición, y al no acompañar al sustantivo ars, no tenemos en el conjunto de los textos latinos el sintagma ars topiaria. Lo cual no significa que la topiaria no fuera un arte. Paradójicamente el hecho de que topiaria no aparezca junto a ars más bien refuerza la idea de que a mediados del siglo I a. C. se consideraba ya un arte, puesto que se presuponía tal condición. La

17 John Dixon Hunt, Gardens and the Picturesque. Studies in the History of Landscape Architecture, Cambridge/London MIT Press, 1993, p. 100. 
elipsis de ars permite sustantivar el adjetivo topiaria, a imagen de poetica, rhetorica, oratoria, venatoria, aedificatoria, coquinaria o incluso amatoria.

El párrafo "fundacional" del ars topiaria es el que Cicerón dirige a su hermano Quinto (ad Quintum 3, 1,5). Merece que lo leamos y traduzcamos de nuevo, combinando las lecciones de Grimal ${ }^{18}$ con las más recientes de Viscogliosi ${ }^{19}$ y ofreciendo perspectivas nuevas: "topiarium laudavi. Ita omnia convestivit hedera, qua basim villae, qua intercolumnia ambulationis, ut denique illi palliati topiariam facere videantur et hederam vendere" ("Elogié al jardinero paisajista (topiarium). Había revestido todo de hiedra, tanto la terraza sobre la que se levanta la villa como los espacios entre las columnas del paseo, de modo que parecía que las estatuas griegas eran modelos de jardinería artística (topiaria) y que estaban vendiendo hiedra').

La indeterminación en Roma del ars topiaria deja también muy abierto el estatuto, el rango y las tareas del profesional que la ejerce. El topiarius se nos revela como un artesano, a veces artista, que se desgaja de la figura del hortulanus. Viscogliosi, cauto en sus hipótesis, se pregunta: "Le sue competenze oltrepassavano quelle dello scultore, sfioravano quelle del pittore, prevedevano quelle dell'architetto e del giardiniere, e tutto ciò senza derivarne una denominazione precisa?" ${ }^{20}$. Después de calificar al topiarius como "poliedrica figura professionale", concluye que no puede quedar, según estaba hasta ahora "confinato nel troppo angusto limite di una certa fantasia e abilità nel condurre e nel potare cespugli e arbusti" 21 . De ahí que debamos estimarlo un paisajista más que un jardinero. Grimal ponía entre comillas la posibilidad de que fuera un jardinero: "Je fis des compliments au 'jardinier"') 22 . El topiarius no equivale al hortelanus, sus tareas no se superponen más que parcialmente; a veces, en nada. Podía tratarse de un jardinero artístico, no de un simple jardinero artesanal ni tampoco de un hortelano. Y del exceso se desprende su fallo, porque da la impresión de que "se le ha ido la mano" recubriendo todo de hiedra, incluso las estatuas griegas. Las comillas de Grimal acaso encumbran su

18 Grimal, op. cit., p. 90.

19 Viscogliosi, op. cit.

20 Ibidem, p. 18.

21 Ibidem.

22 Grimal, op. cit., p. 90. 
irónica interpretación del texto ciceroniano: "On devine que, dans cette lettre familière, Cicéron fait une allusion ironique à une mode relativement nouvelle, qu'il ne veut pas avoir l'air d'adopter aveuglement" ${ }^{23}$. Por su parte, Viscogliosi no excluye que Cicerón esté elogiando aquí en serio la tarea del jardinero artístico: "resta poi da stabilire in che senso vada interpretato il passo ciceroniano, se sinceramente elogiativo, sarcastico, o forse solo lievemente sfottente" ${ }^{24}$. Semejante gama de asedios a la noticia ciceroniana nos deja algunas certezas: a mediados del siglo I a. C. la topiaria es un arte reciente, relativamente consolidado, de origen griego. Consolidado en la práctica, pero no en la teoría. Es importante precisar que las dos facetas resultan imprescindibles en un ars: destreza y excelencia en el oficio, transmisión de esa sabiduría mediante un manual, normalmente redactado por un maestro, con vistas a las generaciones futuras. Así funciona la codificación grecorromana del conocimiento. A la práctica de los jardineros les falta todavía algún conocimiento que será fundamental para nuestra idea de su ámbito de trabajo. Y, desde luego, le falta la sistematización en un tratado de topiaria, que hubiera dado otro sesgo a la crítica del Arpinate.

Si situamos este pasaje en su contexto, vemos cómo felicita (irónicamente) al jardinero artístico (“topiarius”), y unas líneas más arriba elogiaba (esta vez del todo en serio) a su capataz: "Nicephorum, villicum tuum, sane probavi" ("Le mostré mi rotunda aprobación a Nicéforo, tu capataz"). En el rango de los trabajadores, el topiarius (jardinero artístico) es una variante del hortulanus (jardinero, hortelano), y está a las órdenes del villicus (capataz, encargado, granjero), del mismo modo que espacialmente los topia forman parte del hortus, y este de la villa. Frente a los excesos concretos de un determinado jardinero, incluso un helenizado bilingüe como Cicerón se reserva la posibilidad de mostrarse elegantemente crítico; eso sí, en una carta a su hermano, con toda la confianza que le daba el tono coloquial, aunque no exclusivamente íntimo, pues sabe que será publicada. Hay que tener en cuenta que Cicerón detalla las opciones de las que dispone el topiarius: recubrir con plantas trepadoras, seleccionar especies distintas, hermosear con estatuas y fuentes, etc. Sin embargo, no han aparecido todavía las podas artísticas que daban forma a árboles y

23 Ibidem, p. 90.

24 Viscogliosi, op. cit. 
arbustos. Esa invención es de época augústea y se irá incorporando desde entonces al ars topiaria: el caballero Cayo Matio, amigo de Augusto, descubrió los nemora tonsilia ("las frondas podadas artísticamente"). La noticia la recogió con gran exactitud Plinio el Viejo, N.H. 12,13: "C. Matius ex equestri ordine, Divi Augusti amicus, invenit nemora tonsilia intra hos LXXX annos" ('Cayo Matio, amigo del divino Augusto y miembro de la caballería, inventó las frondas podadas artísticamente hace unos ochenta años').

También se muestra muy exacto Grimal al precisar el periodo transcurrido entre la invención de la poda artística y su traslación a la latinidad por Plinio el Viejo: menos de veinticuatro años ${ }^{25}$. No deja de ser curioso que un historiador romano de la ciencia y de la cultura - pues lo eranos ofrezca una datación y atribución tan rigurosas para una innovación menor (la poda para obtener formas esculpidas) en un ámbito relativamente específico como es el del paisajismo.

Hay otra irónica censura sobre los excesos de los jardines elegantes. Se halla en la Vida de Adriano que nos transmite la Historia Augusta. Si fuera fiable, cosa incierta, porque verdad y ficción difícilmente se deslindan en la Historia Augusta, tendríamos una pista postclásica recogida en época tardía. Adriano encarna una virtud militar austera y ordena destruir los jardines artificiosos (“topia”). Un bando doblemente significativo: por tratarse de un gobernante filoheleno — que parece recuperar la sencillez tradicional romana-y por ser el que luego mandará construir los refinados jardines de la Villa Adriana:

Exemplo etiam virtutis suae ceteros adhortatus, cum etiam vicena milia pedibus armatus ambularet, triclinia de castris et porticus et cryptas et topia dirueret, vestem humillimam frequenter acciperet (Scriptores Historiae Augustae, De Vita Hadriani 10.5.1).

Animaba a los demás también con el ejemplo de su virtud, ya que hacía marchas armado por espacio de veinte mil pasos, hacía demoler los suntuosos comedores de los cuarteles, los pórticos, las grutas artificiales y los jardines, vestía con frecuencia una indumentaria muy sencilla.

25 Grimal, op. cit., p. 91. 
Ofrezco la traducción de Picón y Cascón quienes anotan: “topia: jardines artificiales al aire libre, con los que los soldados intentaban paliar los rigores del sol"26. Nótese cómo el excesivo artificio de esas zonas constituía también un factor de debilidad para las tropas.

Pero volvamos a Cicerón y al momento clásico. Su apunte resulta asimismo de orden práctico: es la impresión de un "espectador" que anota un exceso (o lo critica irónicamente mediante la felicitación al jardinero). Si hubiera existido un ars topiaria de referencia, que conociesen ambos (el jardinero autor del jardín de esa villa y Cicerón como espectador-receptor), su azote habría podido enmarcarse mediante una alusión a tal, que a todas luces no existía. Es más, tampoco parece haber existido después en el mundo romano un ars topiaria teórica, ni en prosa ni en verso, un arte de la jardinería exclusivamente artística o paisajística, que por su propia naturaleza se hubiese adscrito al género didáctico. Sí podemos hacernos una idea de cómo era la práctica, fruto de las noticias de los escritores antedichos (que son receptores de jardines, digámoslo así), concentrados en torno a los siglos I a. C. y I d. C. La topiaria en el siglo I a. C. es un arte minoritaria, naciente todavía, incompleta, no autónoma y de índole exclusivamente práctica; basada en la destreza de cada profesional y, por ello, susceptible de muchas variaciones.

Aparte del registro de la voz topiaria en Cicerón, constan otras 21 apariciones de topiarius, sustantivado de dos maneras distintas: en masculino, referido al profesional de los jardines (topiarius también en Cicerón); y en neutro, a propósito de su obra (topiarium opus). Casi todas se dan en Plinio el Viejo (15) excepto 3 testimoniadas por el Digesto de Justiniano. Aunque sean textos significativos, llama la atención su corto número.

\section{Hacia un tRatado TEÓRICO-PRÁCTICO DE JARDiNERÍA}

¿La escasez de testimonios sobre la jardinería artística en Roma supone que carecemos de un arte de la jardinería en latín, entendido como conjunto teórico que transmita los saberes prácticos? De la jardinería artís-

26 Historia Augusta, eds. y trads. Vicente Picón y Antonio Cascón, Madrid, Akal, 1989, p. 58. 
tica muy refinada o del paisajismo exento, no. De la jardinería tal como la entendían los romanos, sí. Al menos podemos asistir a su progresiva configuración. Se produjo una conquista gradual de la autonomía del arte de los jardines que, en la historia de los textos, discurre en paralelo a la propia evolución de los jardines, a su arte práctico de la jardinería en Roma: tanto del hortus como del paisajismo (topiarium opus). Debemos inscribir el arte teórico de la jardinería dentro del arte general del cultivo del campo en Roma, que es uno de los que mejor se nos ha conservado en latín y probablemente no sea un hecho causal. Como afirma Bejarano "no fue el subgénero literario de la agronomía el que peor parado salió del naufragio en el que, en la Antigüedad tardía, se perdieron tantas obras de la literatura romana" ${ }^{27}$. Durante las últimas décadas se ha consolidado la división de la historia de la literatura romana (y la de la misma Roma) en cuatro épocas: preclásica (o arcaica, s. III-s. II a. C.), clásica (s. I a. C), postclásica (s. I-s. III d. C.) y tardía (s. IV-s. VII d. C.). Afortunadamente disponemos de siquiera un tratado de agronomía en cada una de ellas; completos todos, entendidos como manuales dirigidos al dueńo de una propiedad, en la que no siempre hay jardines y mucho menos zonas artísticas (topia).

Los cuatro guardan entre sí una relación genealógica que nos permite ver las cosas con claridad tanto en el género didáctico como en las prosas técnicas. De la época arcaica se conserva el De Agricultura de Catón: la única obra íntegra en prosa de aquellas centurias. Estamos lejos todavía de la jardinería. De la época clásica data otro libro en prosa: las Res rusticae de Varrón. A la postclásica (la primera época imperial, los albores de la que antes se llamó la edad argéntea), pertenece la Res rustica de Columela y en la tardía escribió Paladio su Opus agriculturae, que no se evoca en el panorama de $\mathrm{Grimal}^{28}$, toda vez que hasta hace poco se lo estudiaba dentro del mundo medieval más que ligado al antiguo. Varrón conoce la obra de Catón. Columela maneja la de sus dos predecesores. Paladio está familiarizado con la de Columela, pero casi seguro que ignora las de Catón y Varrón. Sin embargo, esta serie quedaría incompleta sin un hito que, en

27 Virgilio Bejarano, "Prólogo", en José-Ignacio García Armendáriz, Agronomía y tradición clásica: Columela en España, Sevilla, Universidad de Sevilla - Universidad de Cádiz, 1995, pp. 9-11 (p. 9).

28 Grimal, op. cit. 
el centro mismo de la serie, inclinó las cosas hacia el lado de los jardines: las Geórgicas de Virgilio. Nuestra primera tentación es pensar que, por su sensibilidad como poeta y por la belleza de sus hexámetros, habría sido el mantuano quien dio entrada — por la puerta grande — al arte de los jardines en las letras latinas. Pero no fue así, aunque su intervención resultó decisiva. No abrió la puerta, porque Virgilio se atuvo al arte de la agricultura. Su tratado es más poético que técnico: el cultivo de jardines no disfruta de un tratamiento autónomo. Y sin embargo, fue el que entreabrió la puerta cuando encomienda a la posteridad, casi a modo de testamento, que otro se encargue de alumbrar un libro sobre los huertos o jardines. ¿Qué tenía en mente Virgilio, en plena época augústea? ¿Un libro ceñido al cultivo utilitario del huerto? No parece probable, habida cuenta de que ya en época de Cicerón la jardinería artística (y nos lo confirma la arqueología) se había adueñado de villas urbanas y suburbanas. Nada más coherente con el tono de poética didáctica de las Geórgicas que un volumen sobre los jardines (incluyendo su faceta artística) escrito en hermosos hexámetros.

El encargo de Virgilio deja constancia de una elipsis y se propone como prolepsis: anticipa un posible texto de otro ingenio acerca de los huertos/jardines. No hace falta recordar aquí que la literatura latina es una literatura de corpus, pero quizá sí sea necesario refrescar la metáfora del término corpus: un acervo de textos organizado por el tiempo, el azar y los filólogos, pero también, como vemos aquí, articulado conscientemente por los propios autores, que dejan obras por hacer, casillas por rellenar dentro de la cuadrícula de un corpus dotado de sentido por Virgilio y Columela y luego por sus lectores. En ese conjunto las partes guardan relación con el todo. Para el caso del surgimiento del arte literario de la jardinería, esto se percibe como una línea clarísima. El impacto virgiliano divide por la mitad la serie de los tratados agrícolas. Los anteriores a él (Catón, Varrón) se quedan en el dominio general de la agricultura y se compusieron en prosa. Los posteriores a él (Columela, Paladio) serán en su mayor parte agronómicos (y en prosa), pero con secciones autónomas que cabe considerar tratados de jardinería que abrazan el verso.

Reparemos en el libro IV de las Geórgicas. Mientras describe la tarea del mítico anciano de Tarento que cultivaba su huerto, Virgilio está a punto de salirse del terreno de la agricultura: 
[...] illi tiliae atque uberrima pinus, quotque in flore novo pomis se fertilis arbos induerat, totidem autumno matura tenebat. Ille etiam seras in versum distulit ulmos eduramque pirum et spinos iam pruna ferentes iamque ministrantem platanum potantibus umbras. (Georg. 4,141-146)

Así es lo que plantó con mano pródiga tilos y pinos. Cuanta fruta el árbol en las flores vernales prometía, otra tanta rendíale el otoño madura ya. Prodigios de trasplantes realizó con los olmos ya crecidos que ponía en hileras, con peruétanos ya duros, con ciruelos espinosos que injertados cargaban, con los plátanos que ya a los bebedores daban sombras ${ }^{29}$.

Está claro que coquetea con la descripción de un jardín. Y que corrige, con una conciencia autorial que apunta al nacimiento de los tratados de horticultura y jardinería, situando ese futuro origen en su continuidad poética. Implícitamente solicita que se haga en el género de la didáctica técnica y poética, en hexámetros dactílicos que, deudores de Hesíodo y de los presocráticos, pasan por Lucrecio y por el propio Virgilio y conquistarán su lugar en la futura latinidad, a zaga del ya conquistado por los jardines. La teoría viene después de la práctica:

Verum haec ipse equidem spatiis exclusus iniquis praetereo atque aliis post me memoranda relinquo.

Mas propasando estoy mis propios límites.

Queden estas materias para el vate que un día en pos de mí tratarlas quiera ${ }^{30}$.

29 Virgilio, Virgilio en verso castellano: Bucólicas, Geórgicas, Eneida, trad. Aurelio Espinosa Pólit, México D.F, Jus, 1961, p. 169.

30 Ibidem, p. 169. 
"Estas materias", tal como lo vierte Espinosa, son el cultivo del huerto y del jardín, que aquí todavía no se separan. En un artículo de título esclarecedor ("La omisión de la horticultura en las Geórgicas. ¿Planificación política o sentimental?”), Mariner se muestra incrédulo respecto a la idea de que Virgilio haya renunciado a su arte de los jardines por falta de espacio o de fuerzas ${ }^{31}$. La principal razón parece ser de índole política: las directrices augústeas conducían a los grandes cultivos agrícolas. El huerto (y no digamos ya el jardín) aparecen como tentaciones individualistas o esteticistas que el poeta debe evitar. Mariner capta muy bien los pequeños placeres del huerto, casi del jardín: "la horticultura es «muy entretenida» en ambos sentidos del término: no sólo requiere muchísimo tiempo, muchísimas horas; ahí no vale el arado - la única máquina que tenían los romanos—, ni siquiera casi la azada: el azadón, el rastrillo" 32 . Su conclusión — añadimos nosotros — vale casi más para la jardinería que para la horticultura de subsistencia. Estamos a un paso de cruzar la frontera del placer y la geometría que Virgilio evita y que encomienda a poetas futuros. Los términos de la explicación de Mariner convienen más al jardín que al huerto: "cosa delicada, tarea artesana. Y hay que trazar las acequias, los cuadros: actividad geométrica..."33. En época de Augusto, según avanzamos, es cuando un amigo del Príncipe "inventa” —la noticia es de Plinio en su Historia Natural 12-13 - la poda geométrica de la vegetación de jardines. He aquí los peligros individualistas y esteticistas que debía evitar Virgilio: los de los topia dentro del hortus, más aun que los del hortus dentro del ager.

Grimal se muestra convencido de que Virgilio hubiera querido cantar jardines "le véritable développement sur les jardins qu'il aurait voulu écrire demeure interdit au poète" ${ }^{34}$. Por razones filosóficas y de lógica interna: su didáctica del cultivo del campo era incompatible con su concepto de

31 Sebastián Mariner Bigorra, "La omisión de la horticultura en las Geórgicas: ¿̨planificación política o sentimental?", Alicante, Biblioteca Virtual Miguel de Cervantes (reproduce el texto incluido en Virgilio. En el bimilenario de su muerte, Buenos Aires, Parthenope, 1982, pp. 71-82), 2006, http://www.cervantesvirtual.com/nd/ ark:/59851/bmcjq1c7 [consulta 1-octubre-2021].

32 Ibidem.

33 Ibidem.

34 Grimal, op. cit., p. 385. 
jardín, cuya imagen estaba "dans la vie urbaine”35. ¿Cómo sorteó esa contradicción? Con la leyenda del anciano de Tarento, que cultiva su propio terreno, un hortus ideal, no real, un paraíso filosófico, que no es huerto, ni vergel, ni jardín de placer, pero es "todo eso a la vez y más aún" 36 . Concluimos, pues que Virgilio está tentado de hacer una incursión en el arte de la jardinería, desviándose del de la agricultura. No puede hacerlo, lo expresa mediante una especie de praeteritio (sugiere indirectamente lo que podría hacer, lo bordea con una bella descripción, al tiempo que lo descarta) seguida del encargo para que lo hagan los venideros. Aquí también nos separamos de Grimal: Virgilio no cede a los poetas posteriores la descripción de los jardines sino la escritura de un arte de los jardines a la altura de su propio arte de la agricultura. Con esta operación, el concepto de ars aplicado a la didáctica (futura) de los jardines ańade la belleza a la precisión, algo que se da en su plenitud clásica dentro de la poesía. Por eso, sin ir demasiado lejos, nacieron en verso las artes de Horacio (poética) y de Ovidio (amatoria).

El encargo virgiliano lo cumpliría Columela de un modo singular. Once de sus doce libros están escritos en prosa. Siguen a Catón, a Varrón y a otros tratadistas griegos y romanos. Esos once libros son, en todos los sentidos, prosaicos. Pero uno de ellos avanza en hexámetros: es un libro poético, fiel heredero de las disposiciones casi testamentarias de las Geórgicas. Nos referimos al libro X, dedicado a los huertos/jardines. Si antes había tratado Columela las técnicas agropecuarias - por un lado del cultivo de cereales, legumbres y de la vid, las clases de suelo, el olivo y los frutales; por otro, todo lo relativo al ganado-, al concluir el libro IX anuncia que va a cumplir el deseo de Virgilio, respondiendo a las peticiones que le hicieron Publio Silvino y Galión (muy probablemente M. Anneo Novato, el hermano de Séneca). Y con hechura de poema:

Sed iam consummata disputatione de villaticis pecudibus atque pastionibus, quae reliqua nobis rusticarum rerum pars superest, de cultu hortorum, Publi Silvine, deinceps ita ut et tibi et Gallioni nostro conplacuerat, in carmen conferemus (De re rustica, 9.16).

35 Ibidem, p. 385.

36 Ibidem. 
Mas, una vez que hemos concluido el tratado de los ganados y de las crías de la casa de campo, vamos a dar en verso (para darte a ti y a nuestro Galión gusto) lo que nos queda que explicar de las cosas del campo, esto es, el cultivo de los huertos ${ }^{37}$.

\section{Así empieza el libro X, De cultu hortorum:}

Quare cultus hortorum, quorum iam fructus magis in usu est, diligentius nobis, quam tradidere maiores, praecipiendus est, isque, sicut institueram, prorsa oratione prioribus subnecteretur exordiis, nisi propositum meum expugnasset frequens postulatio tua, quae praecepit, ut poeticis numeris explerem georgici carminis omissas partis, quas tamen et ipse Vergilius significaverat posteris se memorandas relinquere. Neque enim aliter istud nobis fuerat audendum quam ex voluntate vatis maxime venerandi (De re rustica, 10, 3).

Y este tratado lo daría yo en prosa, como me había propuesto para ponerlo a continuación de los libros anteriores, si no hubieran combatido mi determinación tus repetidas instancias que me han venido a completar en verso las partes omitidas en el poema de las Geórgicas que el mismo Virgilio había dado entender que las dejaba a la posteridad para que los tratara después de él. Pues nosotros no nos debíamos atrever a esta empresa de otra suerte que por la voluntad del más respetable poeta (traducción de Álvarez de Sotomayor y Rubio, 2005: 389-390) ${ }^{38}$.

Pocas veces en la historia de la literatura universal se leerá una vinculación textual — diríase una intertextualidad perfecta - tan explícita como la que Columela establece aquí con Virgilio. García Armendáriz sintetiza la diferencia de este tratado:

Escribe el libro X, con más neta ambición literaria que los anteriores, siguiendo la estela de las Geórgicas virgilianas y la tradición del poema didáctico alejandrino. La galanura del estilo, la brillantez y

37 Columela, Los doce libros de agricultura, trad. Juan María Álvarez de Sotomayor y Rubio, Segovia, Junta de Castilla y León (facsímil de la edición de Madrid: Imprenta de D. Miguel de Burgos, 1824), 2005, p. 385.

Ibidem, pp. 389-390. 
colorido de las descripciones priman en él sobre la precisión técnica que caracteriza los restantes libros ${ }^{39}$.

Hay en el De cultu hortorum mucho de huerto para la alimentación (puerros, lechugas, altramuces), pero también ya de jardín placentero para la vista, para el olfato, en cada flor y en su combinación. Aunque estemos dentro de una operación literaria y Columela esté mirándose en el espejo de Virgilio, o precisamente por eso, "le sentiment très réel du 'végétal' qui possèdent les Romains" se aprecia en su obra "dont le petit poème, bien qu'il ait surtout un but utilitaire, ne dédaigne pas les menues descriptions poétiques" ${ }^{20}$. Matizaremos este corolario: los pasajes bellos de Columela no contradicen la utilidad. Al contrario, refuerzan su tratado sobre los huertos como un verdadero arte de jardinería. El hortus que enseña a configurar posee zonas útiles (huerto), y asimismo otras hermosas (verdaderos topia, jardín elegante) en los cuales prevalece el placer de los sentidos y de la inteligencia. La descripción poética de cada flor y de sus agrupaciones se recrea en el objetivo al que debe aspirar su lector/aprendiz. Hay belleza, naturalmente, pero también los pasajes que se antojan más prácticos están orientados al regocijo final: así los que enseñan a abonar las plantas, a protegerlas de la lluvia, del granizo, de los gusanos y de otras plagas... Todo eso, como sabe cualquier jardinero, resulta clave para alcanzar, después del trabajo, la postrera belleza, ya de cuño paisajístico $(10,94-105)$ :

Verum ubi iam puro discrimine pectita tellus deposito squalore nitens sua semina poscet, pingite tunc varios, terrestria sidera, flores, candida leucoia, et flaventia lumina caltae, narcissique comas, et hiantis saeva leonis ora feri, calathisque virentia lilia canis, nec non vel niveos vel caeruleos hyacinthos. Tum quae pallet humi, quae frondens purpurat auro, ponatur viola, et nimium rosa plena pudoris. Nunc medica panacem lacrima, sucoque salubri glaucea, et profugos vinctura papavera somnos spargite, quaeque viros acuunt armantque puellis.

39 García Armendáriz, op. cit., p. 29.

40 Grimal, op. cit., p. 280. 
En fin, cuando la tierra ya esté limpia,

en eras dividida, y (su dureza

domeñada) reclame el beso amante

de la semilla, désela y produzca

de flores un terrestre firmamento

el cándido alhelí, la rutilante

caléndula dorada, del hermoso

narciso las guedejas, las terribles

abiertas bocas de león rugiente,

la azucena fragante — esplendorosa-,

albinos o cerúleos los jacintos,

amarilla y morada la que esparce

su olor — cual la virtud, aunque escondida-

violeta; por humilde, más preciada.

Y la purpúrea rosa, sol del prado,

tipo de las que pinta en las mejillas

el cálido pudor de las doncellas ${ }^{41}$.

Es más, creo que en el mismo hortus se distinguen zonas claramente dedicadas al consumo (nuestro "huerto") y otras plantadas por gusto, donde cada una de las flores aporta su color, su forma, su perfume y su simbolismo; y todas juntas generan un cuadro artesanal o artístico dentro del hortus: unos topia. Esta frontera se cruza en más de una ocasión. Hay pasajes en que Columela se dirige al hortelanus como a un verdadero jardinero:

invigilate, viri; tacito nam tempora gressu

diffugiunt nulloque sono convertitur annus.

(De re rustica 10, 159-160)

Hortelanos, alerta, porque el tiempo

huye con pasos sordos, y volando

el año silencioso se desliza ${ }^{42}$.

41 Álvarez de Sotomayor y Rubio, trad. cit., p. 398.

42 Ibidem, p. 399. 
De la tierra nutricia habla Columela en términos que nos hacen pensar en un auténtico jardín (De re rustica 10, 164-165):

\section{viridi redimite parentem}

progenie, tu cinge comas, tu dissere crinis.

Arreglad su tocado y que la cubra su rica y matizada cabellera ${ }^{43}$.

Y aunque pasa a tratar productos de la huerta como puerros, zanahoria y azafrán, de pronto adopta una perspectiva estética, más de florista que de recolector (De re rustica 10, 174-177):

\section{Et male damnati maesto qui sanguine surgunt Aeacii flores inmortalesque amaranti et quos mille parit dives natura colores disponat plantis holitor, quos semine sevit.}

Las que sembró semillas, ramos forme el hortelano de las flores bellas de Éaco y las que nacen de la sangre del varón condenado injustamente, y de los inmortales amarantos, y la infinita copia de colores que pinta la feraz naturaleza ${ }^{44}$.

Álvarez de Sotomayor traduce desordenando los versos. Pero el hortus ya no es "huerto" sino "jardín", genuino opus topiarium si atendemos a su naturaleza de cuadro. En su paráfrasis se usa el verbo "pintar", en el original "parit", "engendra", referido a los colores: et quos mille parit dives natura colores ("los mil colores que engendra la feraz naturaleza"). En este punto, el hortelano, antes cultivador de legumbres (holitor), deviene jardinero con criterio y gusto: disponat. Se hace efectiva así la dispositio, capital en la ordenación del lenguaje y de la obra de arte. Lo otro, lo que da la naturaleza, se reduciría a la materia que proporciona la inventio.

43 Ibidem, p. 399.

44 Ibidem, p. 400. 
García Armendáriz ha estudiado en detalle los valores poéticos del libro X de Columela, abundando en su calidad estética: "Entre todas las flores reina la rosa, especialmente consagrada a Venus; hasta tres veces $(261,287,306)$ se la nombra en este cuadro central del poema, y esta predilección debe probablemente interpretarse en relación con un significado simbólico y poético" ${ }^{45}$. Si nos fijamos bien, García Armendáriz —uno de los mejores conocedores del texto- describe la écfrasis que Columela hace de las flores en el hortus como "el cuadro central del poema", es decir, como una composición de colores, formas y geometrías. Unos topia, un espléndido jardín dentro del huerto. De modo que el objetivo de Columela no es la écfrasis como tal, sino que la belleza se orientase a la didáctica general del poema. García Armendáriz recuerda que en todos los libros de la obra "resulta evidente la voluntad de conjugar doctrina y estilo, si bien en el décimo es posible pensar que la importancia de ambos componentes se invierte, o bien que los planos de significación son de otro orden" 46 .

Tal como funciona ese "cuadro central" dentro del poema (o de la obra), el jardín destaca dentro del huerto. También el traductor ha percibido que estamos ante la composición vegetal de un cuadro, unos topia: el lector ideal (el destinatario) de este maestro de horticultura no será sólo un hortelano, sino un jardinero cuyo perfil cambia según cambia la faz del poema, a medida que celebra las cualidades de los puerros o el esplendor de las rosas ${ }^{47}$. El poema de Columela se ajusta a la didáctica virgiliana, siendo ya un primer tratado de jardinería autónomo, un verdadero arte de los jardines. Incluso, por momentos, gracias a los topia, un arte del paisajismo. De acuerdo con la lógica de la tradición romana —en el cultivo de la tierra y en la literatura - este libro no se deslinda de la horticulura. El mandato virgiliano y el cumplimiento columeliano explican, de algún modo, la ausencia de tratados de arte topiaria. García Armendáriz entiende este libro como un tour de force fruto de la conjunción de técnica

45 José Ignacio García Arméndariz, "Los huertos de Columela, en prosa y verso", en Paulo Minora. Estudios sobre poesía latina menor y fragmentaria, eds. José Luis Vidal Pérez, José Ignacio García Arméndariz, Adolfo Egea, Barcelona, Publicacions i Edicions de la Universitat de Barcelona, pp. 167-200 (p. 184).

46 Ibidem, p. 174.

47 Álvarez de Sotomayor, ed. cit., p. 400. 
y literatura ${ }^{48}$. Por nuestra parte, ampliamos dicha categoría al esfuerzo magistral por cumplir la muy encriptada encomienda de Virgilio: acuñar un arte completo de la jardinería, inserto en el de la horticultura, y este en el de la agricultura.

El esplendor de la rosa consagra un auténtico jardín entendido como topia (De re rustica 10, 286-293):

Iamque Dionaeis redimitur floribus hortus, iam rosa mitescit Sarrano clarior ostro. Nec tam nubifugo Borea Latonia Phoebe purpureo radiat vultu, nec Sirius ardor sic micat, aut rutilus Pyrois, aut ore corusco Hesperus, Eoo remeat cum Lucifer ortu, nec tam sidereo fulget Thaumantias arcu, quam nitidis hilares conlucent fetibus horti.

Ya se corona el huerto; ya la rosa brilla más que la púrpura de Tiro, y vence en esplendor a la rotunda faz de Lucina, pálida y mudable, aun cuando Bóreas de su trono aleje las nubes, y le bruña el horizonte. Ni Pyrois rojo, ni el ardiente Syrio, tanto esplenden, ni el nuncio de la noche, cuando regresa precediendo al día; ni alegra el tricolor arco celeste de la garrida prole de Thaumante como luce y se alegra el fértil huerto con las hermosas flores que lo bordan ${ }^{49}$.

El cromatismo, los contrastes de luz (radiat, micat, rutilus, fulget, conlucent), la disposición de la rosa entre las flores y de estas en el jardín nos hacen pensar en un cuadro o, como sugiere el traductor que también es un voyeur del texto y del jardín, un intérprete de lo implícito: en un bordado. En unos topia. Por momentos, el De cultu hortorum de Columela

48 García Arméndariz, Agronomía y tradición clásica, p. 33.

49 Álvarez de Sotomayor, ed. cit., p. 406. 
se vuelve un ars topiaria, lo cual nos induce a concluir que hay otra ars topiaria implícita (por omitida) en las Geórgicas de Virgilio.

\section{Paladio}

Durante el siglo IV, como muy tarde a lo largo del V, vivió Paladio, del que conocemos muy poco aparte de su obra, su nombre completo (Palladius Rutilius Paulus Aemilianus), su tratamiento de vir illustris y su inserción plena en la Antigüedad tardía. Gozó de fama por el tipo de propiedad al que alude (la gran villa en el campo) y por el formato de su obra, ya encuadernada como códice (y no en volúmenes), lo cual permitía su manejo como libro de consulta: "su tratado fue la obra de agricultura más leída en el Occidente europeo durante la Edad Media", [a pesar de que su] "contenido [...] era sensiblemente inferior al de sus predecesores" Sin embargo, ¿esa inferioridad también es cierta en la parte más lindera de la jardinería?

García Armendáriz destaca la impronta de la obra de Columela en la de Paladio y "la relación de rivalidad en cierto modo", según la tradición de la aemulatio ${ }^{51}$. Dicha aemulatio, a nuestro parecer, afecta también al desarrollo de un arte autónomo de la jardinería en un libro separado, escrito en verso, en la despedida de un tratado general de agricultura en prosa. Incluso en el detalle de presentar el libro poético con un breve prefacio en prosa siguió Paladio los pasos de Columela.

La sección en prosa del tratado de Paladio — verdaderamente más prosaica - y el libro escrito en verso —realmente más poético- recibieron títulos diferentes y fueron objeto de transmisiones separadas, aunque en principio formaban un todo junto con la Medicina veterinaria: Tratado de agricultura (Opus agriculturae) y Poema de los injertos (Carmen de Insitione), que en principio constituía el libro XV. El Tratado de agricultura (en sentido estricto) en prosa. El Poema de los injertos, en verso, un rosario de diecinueve epigramas, se ha desgajado en las sucesivas ediciones. También aquí Paladio traspasa la misma frontera que Columela, entre la horticultura y la jardine-

50 Ana Moure, en "Introducción” a Paladio. Tratado de agricultura; Medicina veterinaria; Poema de los injertos, ed. y trad. Ana Moure, Madrid, Gredos, 1990, p. 38.

51 García Armendáriz, Agronomía y tradición clásica, p. 43. 
ría. Como su modelo, se orienta hacia un planteamiento de tipo cromático y estético, aunque simula estar preocupado por la productividad.

$\mathrm{Al}$ efecto artístico de las flores y los frutos — que también vienen a configurar una especie de cuadro- contribuye no solo el colorido, sino también el concepto de decus; por ejemplo en el membrillo, esa especie de armonía o de gracia a la hora de valorar plásticamente el fruto que, como se ve, es capaz de aceptar otros pero no permite que el suyo prenda en ningún otro árbol. Todo eso es de raíz virgiliana. El pasaje del libro IV de las Geórgicas en el que Virgilio encomienda los huertos a sus continuadores se cumple en Paladio por segunda vez. De nuevo hace aquí una analepsis (doble) que viene a colmar la elipsis virgiliana y a amplificar el tema de los huertos columelianos. Esta vez enfoca más en detalle que aquel. El gaditano aborda los huertos en general. Paladio, los injertos, que era el asunto del que se iba a ocupar Virgilio. Paladio despliega una amplificación y una concentración sobre Columela. Y la variatio cobra tintes de emulación: Paladio compone una serie de epigramas en dísticos elegíacos. Formalmente ha roto la secuencia hexamétrica virgiliana y columeliana. También es cierto que dicho metro tenía tradición didáctica, especialmente en la poesía amorosa (no hay más que pensar en el Ars Amatoria de Ovidio). Aquí el libro de poemas constituye una monografía sobre el injerto en el huerto/jardín, y a la vez genera en sí mismo un jardín poético en el que se eleva una serie de árboles. Puede afirmarse que por el tono virgiliano, de una didáctica todavía épica, otorga al poema de Columela un rango artístico mayor. Moure ha estudiado la industria de Paladio en el Carmen de Insitione (aceptable incluso en la métrica y el ritmo) y sus elementos retóricos ${ }^{52}$. No obstante, su dictamen es que resulta "artificioso y retórico en su poema sobre Los injertos" 53 . Por nuestra parte, no minusvaloramos la impronta retórica, que es uno de los rasgos de la literatura romana; notorio incluso en grandes poetas como Ovidio. Por otro lado, la dimensión de arte de jardinería no depende de que el tratado posea más calidad poética o se antoje más retórico. Tampoco es necesario que se escriba en verso, aunque este cauce resulte del todo admisible. El entronque con Virgilio - y no deja de ser curioso que cristalice en una especie de injerto textual — no requiere en sí mismo del verso ni de la calidad poética: lo que introdujo Virgilio es la posibilidad, casi la orden,

52 Moure, ed. cit., pp. 13-14.

53 Ibidem, p. 16. 
de que otros traten la materia de los huertos/jardines. Así lo hizo Columela y también Paladio, cuyos poemitas sobre los injertos traslucen destellos de elegante jardinería y sugieren un hermoso paraje, recortando un jardín dentro del huerto, lo cual hemos definido como topia. Por último, no es tanto en el resultado como en la actividad del jardinero donde se aprecia la cercanía con el topiarius: en la delicadeza de la labor de los injertos, presidida por el gusto cromático y los criterios de decus es donde resolvemos que estamos pisando el terreno artístico, el placer de la vista y de la inteligencia que rige los jardines. La conexión directa con la didáctica virgiliana la da el tema mismo de los injertos. Hay un dato a contrario que refuerza dicho vínculo. En el Carmen de Insitione, que entronca con Virgilio tanto como con Columela, se cumple una directriz general de Paladio: omitir la mención del mantuano. "Excluye a Virgilio, que está prácticamente ausente de forma deliberada del tratado de Paladio, pues, hasta en los pasajes donde sigue muy de cerca a Columela, omite precisa y únicamente los versos de Virgilio que muchas veces reproducía este agrónomo" 54 .

Paladio describe las flores o los frutos, el cromatismo. Dice "coloreadas", literalmente "pintadas" (picta) con la metáfora propia de la jardinería entendida como arte del pincel:

\section{DE MALO PVNICO}

Punica non alios umquam dignata sapores mala nec externis adsociata comis, ipsa suas augent mutato semine gemmas et sibi cognato picta rubore placent.

\section{EL GRANADO}

Nunca condescendió el granado a sabores ajenos ni a aliarse con forasteras frondas. Cambiando sus semillas, se recrecen sus yemas y a él mismo le complacen así coloreadas de otro rojo que viene de su hermano de sangre.

54 Ibidem, p. 16. 


\section{DE CERASO}

Inseritur lauro cerasus partuque coacto tingit adoptiuus uirginis ora pudor.

Vmbrantes platanos et iniquam robore prunum conpellit gemmis pingere mebra suis populeasque nouo distinguit munere frondes, sic blandus spargit brachia cana rubor.

\section{EL CEREZO}

El cerezo se injerta en el laurel, y en ese nacimiento forzado un pudor aprendido colorea la faz virginal. También logra que los umbrosos plátanos y el desigual ciruelo maticen su ramaje con las yemas que aporta. Con nuevo don distingue las frondas de los álamos: suave rubor esparce por sus ramas tan blancas ${ }^{55}$.

El juego de colores - los matices, el contraste entre el rojo y el blanco, sea entre flores o frutos, o entre estos y las ramas - nos hace pensar en la pintura $y$, naturalmente, en el huerto convertido en placentero jardín:

DE MALO CYDONEO

Cum praestet cunctis se fulua cydonea pomis, alterius nullo creditur hospitio.

Roboris externi librum aspernata superbit,

Scit tantum nullo crescere posse decus.

Sed propriis pandens cognata cubilia ramis

stat contenta suum nobilitare bonum.

55 Juan Antonio González Iglesias, Anónimos y menores: 12 poetas latinos, Málaga, Rafael Inglada, 1996, p. 14. 
Aunque el rubio membrillo acepta cualquier fruto, no se fía de la hospitalidad, de nadie. Desdeñoso desprecia otra corteza. Sabe que tanta gracia no crece en ningún otro: Ofreciendo su tálamo a ramas de su especie se yergue satisfecho de ennoblecer su esencia ${ }^{56}$.

\section{8. ¿HORTELANO O JARDINERO? UN CASO RARO EN EL HELENISMO ROMANO}

Concluyo con un texto griego del siglo I traducido al latín en época tardía, lo cual sitúa a ambas versiones en los momentos y contextos que nos interesan. Dentro del helenismo romano se registra una sugestiva aparición de un hortelano, o de un jardinero, con doble tradición exegética y artística, que nos ayudará a entender las cosas a la luz de unos testimonios que no se suelen atenderse en el corpus latino ni en el griego. Se trata del célebre encuentro de Cristo Resucitado con María Magdalena: en el Evangelio de Juan, ella lo percibe como un jardinero u hortelano.

Juan (20:15) escribe: "Ella, pensando que era el hortelano, dícele: Señor, si tú lo has llevado, dime dónde lo has puesto" 57 . El original griego dice:

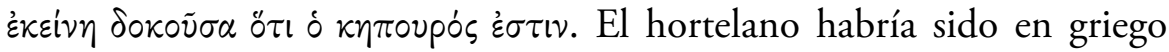
o $\lambda \alpha \chi \alpha \nu \varepsilon u ́ s$. Pero aquí se le aplica al jardinero el sustantivo compuesto

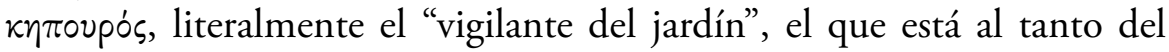
mismo. Desde luego, parece más un jardinero que un hortelano, puesto que se compone de -oupós ('ver, vigilar') y $\kappa \tilde{n} \pi \circ \varsigma$, que es claramente “jardín", más que "huerto". Así, por antonomasia, кñ Epicuro, pero también el jardín de Afrodita, el de Zeus o el de las Musas. Tal vez por el refinamiento pagano del término griego y por sus connotaciones filosóficas, S. Jerónimo lo tradujo como "illa existimans quia hortulanus esset". La identificación de hortus con jardín está clara a finales del siglo IV. Hortulanus puede ser tanto "hortelano" como "jardinero". Lo

56 Ibidem, p 14.

57 La Biblia del Oso. Nuevo Testamento, trad. Casiodoro de Reina, ed. José María González Ruiz, Madrid, Alfaguara, 2001, p. 293. 
atractivo, aunque sea ex silentio (o a contrario, si es que Jerónimo conocía topiarius) es que el traductor no haya elegido el término topiarius (raro, por otra parte en latín) sino hortelanus. El contexto de la Palestina romana del siglo I, el del lugar de un enterramiento y la propia figura de Cristo, hace desde luego más coherente el término hortelanus, aunque sea para alguien que se ocupa de un jardín funerario y no de un huerto. La tradición iconográfica lo ha representado como el que cultiva un huerto, o como el que vela por un jardín sencillo, no como un jardinero paisajista.

\section{Conclusiones}

Creemos haber iluminado cómo en Roma sí se procuró desarrollar un arte de los jardines. Dicha tendencia lleva, como es lógico, un cierto retraso respecto a los jardines reales. Cicerón atestigua la incorporación del jardín plenamente literario y estético a la villa, a la casa. El jardín y la biblioteca forman parte uno del otro, dependiendo de la perspectiva. La prosa del Arpinate informa también de la existencia de un arte de jardinería paisajística a mediados del siglo I a.C. Virgilio en las Geórgicas eludió la tentación de cantar los jardines en un arte específica que enseñara cómo cultivarlos, aunque de algún modo, por la elipsis misma, mostrara interés en hacerlo. Ambos se inscriben en el periodo romano de la humanitas más acendrada: Cicerón en la prosa, Virgilio en el verso. Uno nos presenta los jardines, el otro da el aviso de componer un arte de los jardines. El jardín es sincrónico de la humanitas en Roma porque publica y concreta en el espacio sus mejores atributos: aceptación de los límites, gusto conjunto por la belleza natural y cultural, sensibilidad, empatía, mundo en pequeño... Virgilio encomienda la tarea de gestar un ars topiaria a los futuros poetas. Curiosamente serán dos prosistas los que cumplan en verso tal designio: Columela y Paladio. Los dos mantendrán sus vínculos en prosa con la didáctica de la agricultura — que viene de Catón y Varrón- y también en verso con la didáctica de la horticultura y de la jardinería, que procede de Virgilio, aunque sea por omisión. La tradición romana que va de la época clásica a la tardía consolida algunos pares de vocablos que se anudan en paralelo: el hortus dentro de la villa; los topia dentro del hortus; el topiarius que se independiza progresivamente del hortulanus; las 
artes de la jardinería que se escinden - con título propio e incluso con transmisión textual separada- de la estricta horticultura y, desde luego, de la agricultura. La presencia en los textos o en sus interpretaciones de categorías propias de la pintura confirman que nos hallamos ante la elaboración de un jardín con criterios propios de las artes visuales: ut pictura hortus, ut pictura topia. 